\title{
Reciprocal facilitation and impairment of free recall
}

Three experiments were performed to investigate the effect of facilitating free recall of a subset of items on recall of the remaining items of the set. The facilitation was induced by giving an $E$ Group $5 \mathrm{~min}$ in which to study a list of items forming the subset. Sets used were the States of the U.S.A. and the Counties of England. Immediately following the period of study, both groups attempted free recall of all the set. List study facilitated recall of list items but impaired recall of nonlist items.

Kay \& Skemp (1956) explained their finding that recall can interfere with subsequent recognition on the hypothesis that the presence of strong associations raises the recognition threshold for the weaker ones. One interpretation of this hypothesis is that the presence of well known items raises the criterion for recognition so that less well known items are rejected. However, Brown \& Packham (in press) failed to obtain evidence that recall does raise the recognition criterion, and recall interfered with subsequent recognition in their experiments even though a measure of recognition was used that, based on ranking, was independent of the criterion. A second interpretation of Kay and Skemp's hypothesis is that strong associations block weaker ones. In this form it implies that recall as well as recognition can be affected by differences in strength between associations and it can be considered to include the concept of generalized response competition put forward by Newton \& Wickens (1956). The experiments reported below test this form of the hypothesis by increasing the strengths of half the items from a familiar set by direct study of a list of these items immediately before attempted free recall of all the items of the set. The prediction is that, although recall of list items will be facilitated, recall of the remaining items will be impaired. An opposite prediction could be made by supposing that facilitating the retrieval of some items will assist the retrieval of the remaining items by some form of associative arousal or indirect priming. However, a recent review suggests that such facilitation is unlikely unless there are strong associative links between the items (Cofer, 1967). Method

Experiment 1. University of California undergraduates seated in two rooms were assigned at random to an $E$ group of 33 and a $C$ group of 31 . Each $S$ of the E group recelved a sheet face down containing a list of 25 states of the Union (list states) with the instruction to learn the list without bothering about the order. The $\mathrm{E}$ group then studied the list for $5 \mathrm{~min}$ while the
C group engaged in light reading. Next, Ss were instructed not to talk, the study sheets were collected, and every $S$ received a sheet face down containing the instruction "Write below all the states of America that you can think of. If you were given a list to study, it does not matter whether the states were or were not on your list. You will be interrupted from time to time and asked to draw a line below the last state written down before the interruption." Below the instruction the sheet was divided into three columns and the left-hand one was headed "START HERE." The sheets were turned over about $2 \mathrm{~min}$ after the conclusion of the study period and, after the instruction had been emphasized verbally, free recall commenced and lasted $10 \mathrm{~min}$. At $1 \mathrm{~min}$ intervals the Ss were asked to underline the last state recalled.

Experiment 2. This differed from Experiment 1 in the following ways: (a) the set of items was the 40 counties of England; (b) the 51 Ss were English school children ages 14-16; and (c) the $C$ group drew pictures while the E group studied a list of 20 counties.

Experiment 3. This was identical to Experiment 2 except that all Ss attempted free recall of counties for $6 \mathrm{~min}$ immediately before the rest of the experiment. None of the 52 Ss had participated in Experiment 2. Resulis

Experiment 1. Mean recall by the $\mathbf{E}$ group was significantly above that for the $\mathrm{C}$ group on list states $(t=3.45, \mathrm{df}=62, \mathrm{p}<.01$ ) but significantly below on nonlist states $(t=3.01, p<.01)$ at the end of the 10 min recall period. Figure 1 shows the cumulative recall of nonlist states at the end of each minute by the two groups; there is little sign of the groups converging. There was no correlation between the frequency of recall of a nonlist state by the C group and the difference in its frequency of recall by the two groups ( $r h o=-.05$ ).

Experiment 2. The same trends were obtained as in Experiment 1 but the groups did not differ significantly on recall of either list or nonlist items (counties). The inconclusive results were attributed to the large subject differences present. For example, scores for the control Ss on nonlist counties ranged from 4 to 18 .

Experiment 3. Recall after $6 \mathrm{~min}$ of the final test was compared with recall at the end of the $6 \mathrm{~min}$ of the first test. Recall of nonlist items rose by $11.1 \%$ for the $\mathbf{C}$ group and fell by $10.4 \%$ for the $\mathrm{E}$ group. Both these changes were significant by $t$ test ( $p<$ .05) as was the difference between them $(t=3.17$, 


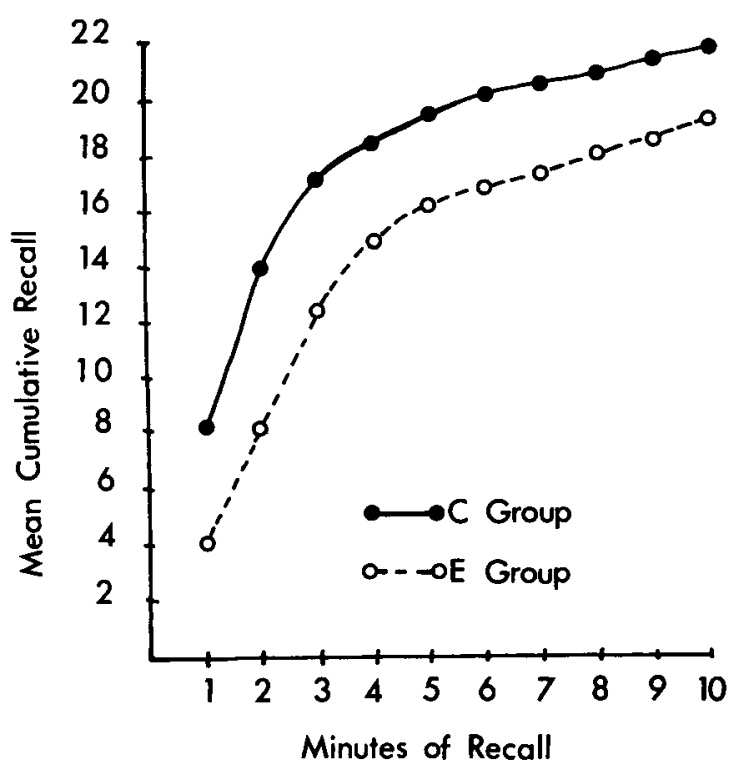

Fig. 1. Recall of nonlist items in Experiment 1.

$\mathrm{df}=50, \mathrm{p}<.01)$, showing that list study impaired recall of nonlist items. The rise for the $\mathrm{C}$ group represents the Warner Brown effect (Brown, 1923). Recall of list items rose for both groups but the rise was significantly higher for the $E$ group $(p<.001)$. As in Experiment 1, there was little sign of the groups converging in their recall of nonlist items during the $10 \mathrm{~min}$ recall period in either Experiment 2 or 3. Discussion

The results of all three experiments accord with the hypothesis that strong associations block weak ones. Strengthening the associations underlying the retrieval of list items impaired the retrieval of nonlist items. One explanation for this blocking is that successive retrievals from memory in free recall are somewhat analogous to sampling with replacement. This will mean that items which have already been retrieved are liable to occur as implicit intrusions while $S$ is attempting to retrieve additional items, especially if the successful retrieval of an item still further increases its strength. This could explain why a limited capacity retrieval system can seem to underlie free recall performance (Tulving \& Pearlstone, 1966).

A less abstract explanation of the present finding is that retrieval strategies are affected. For example, an $\mathbf{S}$ may bring to the experiment his own particular strategy for recalling the states of the U.S.A. If he studies a list containing only 25 states, this may change his strategy when he attempts to recall all the states, with an adverse effect on the retrieval of nonlist states. Individual recall sheets were examined in Experiment 1 to see whether Ss of the $\mathrm{C}$ and $\mathrm{E}$ groups differed in their use of identifiable strategies such as alphabetic or geographical recall. However, those few Ss in either group who started with an identifiable strategy soon abandoned it. The nearest to an identifiable persisting strategy was found in the behavior of five of the $33 \mathrm{Ss}$ of the $\mathrm{E}$ group who wrote down less than four nonlist states in the first $2 \mathrm{~min}$. (This behavior may have been no more than a product of the relative accessibility of list and nonlist states.) A deliberate attempt to pursue this strategy by many $\mathrm{E}$ group $\mathrm{Ss}$ at the outset of the recall period may explain the difference between the groups during the first $2-3 \mathrm{~min}$ of the recall period; it does not explain the persistence of a difference thereafter. The attempt to identify strategies adopted in Experiments 2 and 3 also proved unrewarding.

\section{References}

BROWN, J., \& PACKHAM, D. W. The effect of prior recall on multiple response recognition. Quart. J. exp. Psychol, in press.

BROWN, W. To what extent is memory measured by a single recall? $J$. exp. Psychol, 1923, 6, 377-382.

COFER, C. N. Conditions for the use of verbal associations. Psychol. Bull., 1967, 68, 1-12.

KAY, H., \& SKEMP, R. Different thresholds for recognition - further experiments on interpolated recall and recognition. Quart.J. exp. Psychol., 1956, 8, 153-162.

NEWTON, J. M., \& WICKENS, D. D. Retroactive inhibition as a function of the temporal position of the interpolated learning. J. exp. Psychol, $1956,51,149-154$.

TULVING, E., \& PEARLSTONE, Z. Availability versus accessibility of information in memory for words. J. verbal Learn. verbal Behav., 1966, 381-391.

Note

1. Thanks are due to Miss Lorraine Novinski for help with Experiment 1 and to Mr. David Routh for help with Experiments 2 and 3. 